\title{
Impact on stability of boreholes in brown coal over time and changes to in situ stress
}

\author{
WE Bamford Bamford Rock Testing Services, Australia \\ RS Potdar Bamford Rock Testing Services, Australia
}

\begin{abstract}
Brown coal is a complex geo material that has significantly different behaviour to rocks with regard to how it changes over time and with changes to in situ stress and environmental conditions. Boreholes in brown coal formations are susceptible to in situ radial deformation of the borehole and these changes may have a negative impact on instrumentation installed in monitoring boreholes as the inner walls squeeze the instruments in the radial direction. The data collected by sensors affected by borehole deformations over time may not be completely consistent with the actual long-term in situ properties of the coal. Mining operations near boreholes in brown coal tend to reduce the in situ stresses and this change may contribute to accelerated deformation or collapse of the borehole.
\end{abstract}

Major time dependent changes can also occur in brown coal in the form of mineral creep and creeping from dissipation of micro-pore gas, resulting into movements of joints/micro fractures in the coal matrix. Internal micro-cracking is promoted by the high pressure of entrapped gas present in the micro pores in brown coal matrix at different stages of loading and unloading. Such additional creeping in conjunction with the mechanical creep, leads to unusually high and unpredictable time dependent deformation patterns in the coal mass. Prolonged exposure to oxygen and slow release of internal gas from exposed coal surfaces (for example the inner walls of a borehole) also alter the chemical as well as engineering properties of brown coal, causing further problems in predicting its geotechnical behaviour. These critical time dependent characteristics of brown coal have received minimal attention in the past. The presented paper attempts to highlight these issues of brown coal behaviour and demonstrates the impact of changes in stress regime due to an approaching mine batter near a borehole in brown coal.

\section{Introduction}

In Australia, brown coal is the dominant energy source and over 95\% of Australia's brown coal is found in Victoria (Figure 1). The Victorian brown coal is composed of partly altered plant debris at an early stage of coalification, where the original cellulose in the coal mass has been destroyed, hydrogen, oxygen and moisture are slightly reduced and proportion of carbon has increased. These kinds of changes increase the rank of the coal, leading to its progression towards becoming bituminous and anthracitic coal (Hutton 2009).

To ascertain the geological location, depth and the quality of brown coal, boreholes are drilled into the geological formations. In Victoria, over 9,000 boreholes have been drilled into the brown coal, most of which were re-sealed soon after the extraction of bore logs. Some of these boreholes were utilised for measurement of in situ stress and deformation. 


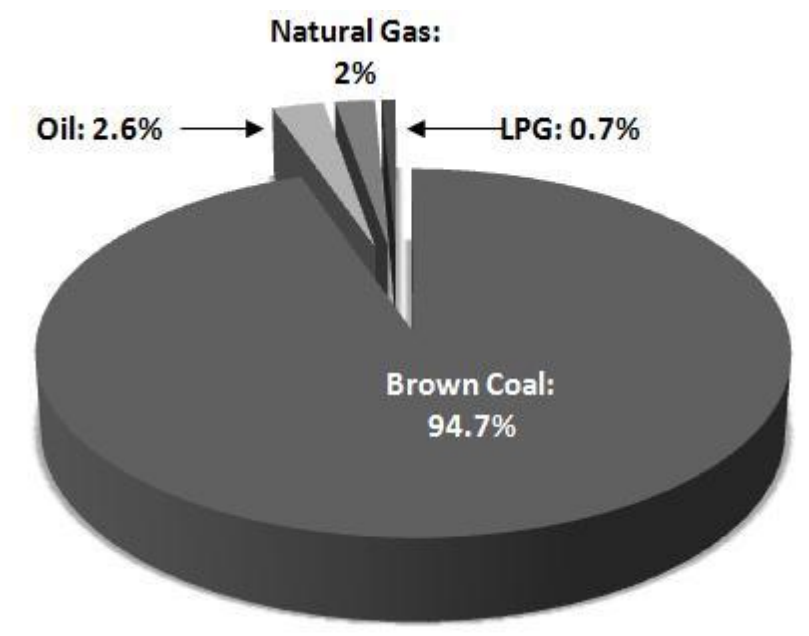

\section{Figure 1 Proportion of Victorian non-renewable energy sources (after Hutton 2009)}

Large man-made excavations such as open cut mines significantly disturb the local stress field in the ground with potential for slow or catastrophic failure. Knowledge of the in situ stresses and material properties of the brown coal is helpful in assessing the potential for instability. The type and extent of breakouts in boreholes or wellbores are considered good indicators of the orientation of the tectonic stress tensor (Guenot 1989). Maximum compressive stress in wellbores usually develops in the direction of minimal principal stress, so in vertical wellbores the breakouts form in the direction of the minimum horizontal stress direction.

High stresses arise at the borehole wall when a wellbore cavity is drilled through a rock mass, which leads to formation of breakouts that enlarge the hole to an elongated shape oriented along the direction of the minimum principal stress (Schoenball et al. 2014). Wellbore breakouts are formed progressively with deepening and widening of the initially damaged zone. These observations have been explained by timedependent brittle creep for many types of rocks in the rock mechanics literature. In this paper, the authors suggest the existence of similar relationship between borehole failures and breakouts with mechanical creep in Victorian brown coal. Schoenball et al. (2014) studied the time dependent mechanical creep and temporal evolution and shape of breakouts in boreholes in different types of rock using a time-to-failure approach. In this approach, the time between the start of the creep experiment to the failure of the rock is related to applied load by an exponential law.

This paper focuses on the contribution of time dependent brown coal properties as well as the effects of nearby mining operations in the failure of a borehole though elastic plastic deformation, breakout development via stress corrosion and subcritical crack growth. Other contributing factors such as chemical changes, the formation of stress solution on crack tips, and changes in pore pressure in the rock can also play a significant role in the evolution and growth of the breakouts, especially in the case of reactive substances such as brown coal, which are beyond the scope of this paper.

\section{Geomechanics of boreholes}

It is importance of understand the geomechanics of a borehole, Backers (2013) discussed this in detail through in situ stress redistribution and crack formation phenomena (Figure 2(a)) and enlisted the important factors to be taken into consideration while planning and drilling of a borehole. For a vertical borehole in a stress field where the vertical stress is a principal stress axis, the local effective radial ( $\sigma r)$ and tangential stresses $(\sigma \theta)$ are trigonometric functions of the principal stresses SH and Sh, the reservoir pressure PP, the weight of the drilling fluid Pm and possible thermally-induced stresses $\sigma \Delta \mathrm{T}$ resulting from any difference in temperature between the rock and drilling fluid (Figure 2(a)). 


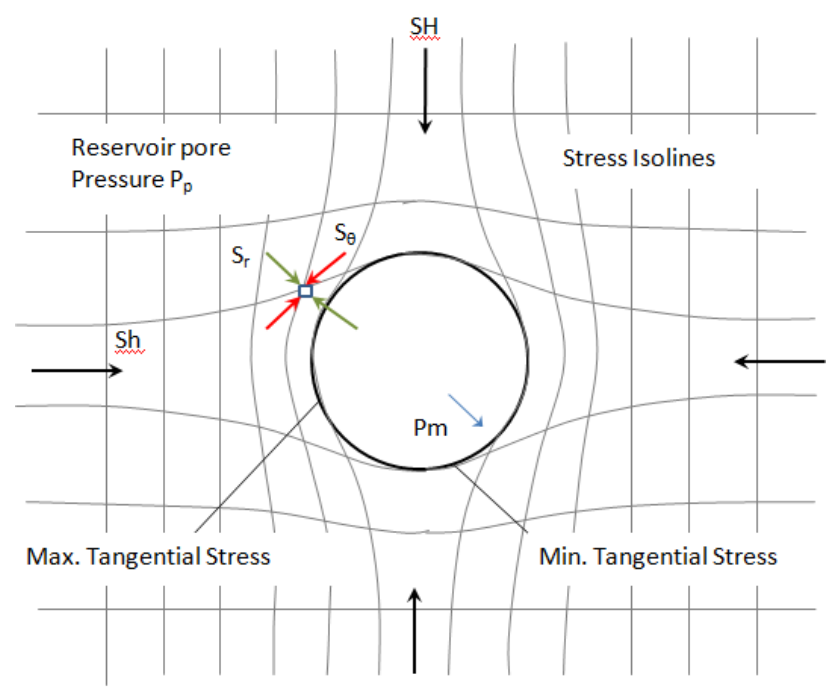

(a)

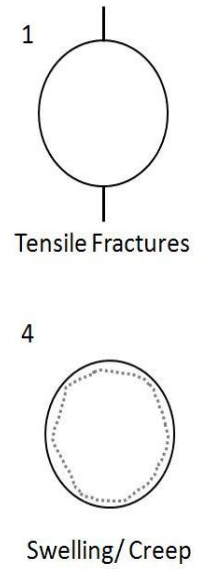

Swelling/Creep

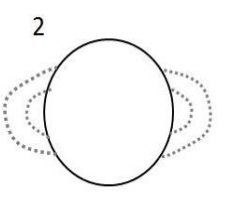

Breakouts (Stable)

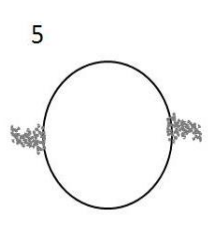

Compaction Bands

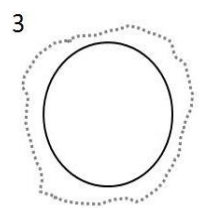

Collapse (Unstable)

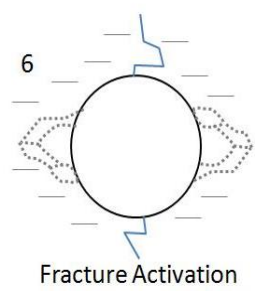

(b)

Figure 2 (a) stress redistribution around a vertical borehole; (b) schematic diagram of phenomena associated with stress redistribution (Backers 2013)

In Figure 2(b) Backers (2013) describe the typical changes in rock mass caused by the alterations of the local stress field and drilling activities and referring to Figure $2(b)$, they are defined as:

1. Drilling induced tensile fractures develop when local tensile stresses exceed the tensile strength of the rock.

2. Boreholes breakouts are developed when compressive stresses exceed the strength of the rock.

3. Borehole collapse when a certain breakout width is exceeded (typically $>90^{\circ}$ ).

4. Swelling or creep, which can reduce the borehole diameter.

5. Compaction bands with significantly reduced porosity.

6. Activation of pre-existing faults or fractures.

Zoback et al. (1985) studied the development of stress-induced breakouts in boreholes using numerical simulation and reported a growth in depth of a breakout; however, not much change in the width. They concluded that the breakout geometry and size could be considered as indicators of stress magnitude in the rocks surrounding the borehole. They reported observing the development of broad and flat curvilinear surfaces that extended the borehole in the direction of the major in situ horizontal principal stress. Similar observations of dilatant micro-cracking in the areas of maximum compressive stress concentration around boreholes in different rocks have also been reported by Haimson (2007).

\section{Borehole geomechanics in brown coal}

Time-dependent brittle creep increases the density of micro-cracks, which in turn leads to degradation of the elastic moduli in a rock material (Heap et al. 2009). Experiments conducted by Heap et al. (2010) show that depending on rock type, the elastic moduli (E) reduces by $10-30 \%$ until the sample reaches macroscopic failure. Heap et al. (2010) report that the Poisson's ratio (v) measured in cyclic uniaxial compression tests increases with increasing damage and progressive stiffness degradation. They also report that damage induced changes in elastic moduli result in significant decrease in differential stress. Past experiments show a strong correlation between micro crack development in rock with decrease in elastic moduli, increase in acoustic emission, strain and change in porosity. Hsieh et al. (2014) state that the nonlinear deformations in rock under uniaxial compression can be attributed to crack closure, sliding, 
compaction and crack generation and also that these irreversible changes in the rock including dilatancy increase the stiffness of the rock when reloaded a second time.

The pore-fluid in rocks has a stabilising effect on the matrix. The propagation of breakout tends to be retarded more in poro-elastic materials than in elastic materials. There is no evidence that increased pore fluid pressure (along with constant effective stress) enhances subcritical crack growth (Schoenball et al. 2014). Schoenball et al. (2014) reported in their numerical analysis, a typical V-shaped breakout geometry that evolves from the time dependent creeping of the rock. This $V$-shaped breakout is attributed to development of an excavation damage zone around the wellbore that reduces stresses in damaged elements. Due to such mechanical damage and degradation, stresses in the rock matrix are redistributed, increasing the load on the remaining matrix of the rock ultimately leading to macro failure.

Drilling of a borehole through a brown coal seam also results in the exposure of the coal surrounding the borehole to environmental elements such as humidity changes, temperature variations and even potential chemical changes due to exposure to oxygen. This alteration of environmental and chemical state leads to changes in mechanical changes in the brown coal characteristics, which are, absent in the case of most other geomaterials. The release of pore gas from the surrounding brown coal also influences the mechanical behaviour of the brown coal but this effect has not been addressed at this stage. Borehole drilling in rocks and soils has been the subject of high quality geotechnical research for decades, but boreholes in brown coal must be treated with a somewhat different approach, in light of the dynamic properties of the brown coal material.

\section{$4 \quad$ Effects of an approaching mine face on borehole integrity}

In a mining operation, the progression of a mine face closer to an existing borehole can cause dramatic changes in the pre-existing stress regimes near the borehole. This disruption is bound to affect the stability of the borehole in the form of elongation of the hole in the direction of the approaching mine face. This phenomenon has been studied in the past for tunnels, and the authors propose that similar observation must be made in boreholes, as both cases deal with a circular cavity in a thick rock stratum. A long vertical borehole in a uniform brown coal formation can be represented as a circular hole of radius, a, located at the origin in an infinite plate of finite thickness, as shown in Figure 3.

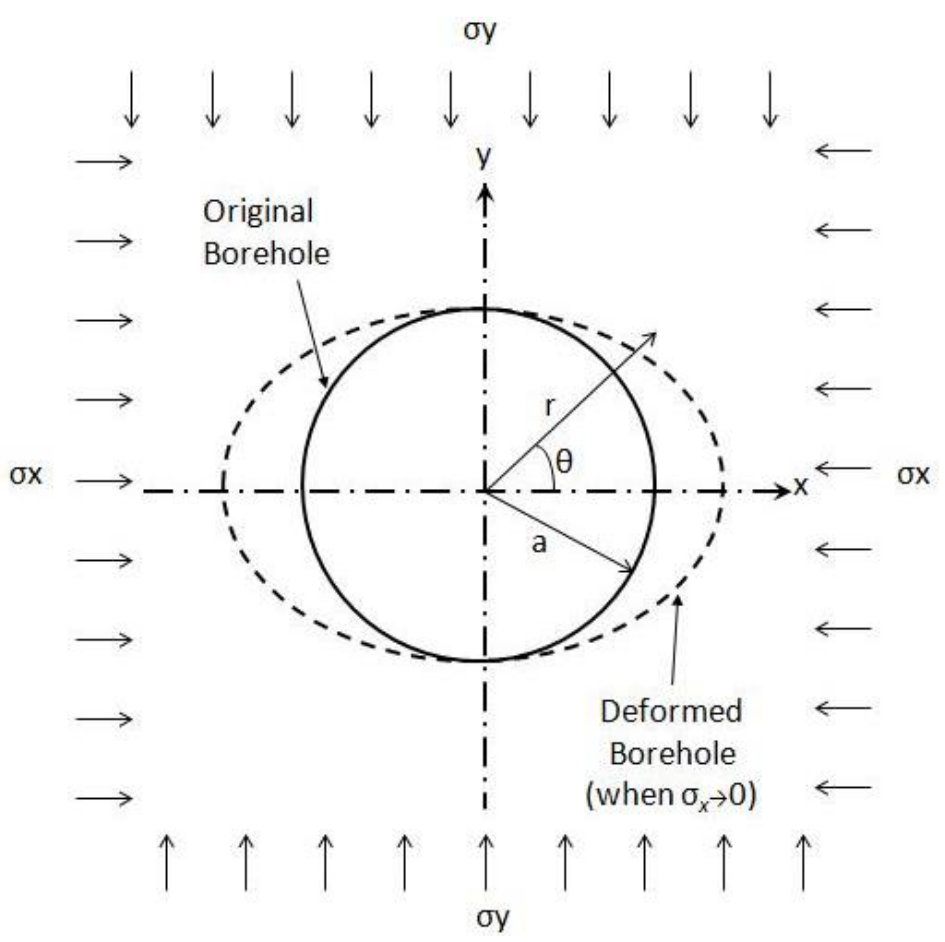

Figure 3 Borehole cross section, original circular shape and elongated deformed shape as mine face approaches from $x$-direction 
For Victoria's Yallourn coal seam, Rosengren predict the horizontal stresses of between 850 and 1,400 kPa. If we assume $\sigma_{x}=1 \mathrm{MPa}$, borehole diameter of $0.3 \mathrm{~m}$, and Poisson's ratio $(v) 0.4$ in elastic phase of deformation, and calculate the Elastic Modulus (E) from Trollope et al. (1965) to be approximately $47 \mathrm{MPa}$, the inward radial displacement of the borehole can be calculated to be approximately $4.5 \mathrm{~mm}$ from the following equation:

$$
\mathrm{u}=\frac{\mathrm{r}(1+\mathrm{v})}{\mathrm{E}}\left(\mathrm{p}_{0}-\mathrm{p}_{\mathrm{i}}\right)
$$

where; $p_{0}-p i=$ horizontal principal stresses and internal pressure in the borehole wall (since there is no lining in the borehole, $\left.p_{i}=0\right), v=$ Poisson's ratio, $E=$ elastic modulus, $r=$ radial distance from centre of borehole. Ramamurthy (2014) explains that according to Kirsch's equation for biaxial stress, the displacement for a plane stress and plane strain case of a circular borehole, the plane strain displacements will be lower by this factor of $\left(1-v^{2}\right)$, i.e. for the plane strain case with biaxial stresses the equations of horizontal displacement, $u$, in $x$-direction is:

$$
\begin{gathered}
\mathrm{u}=\frac{1-\mathrm{v}^{2}}{\mathrm{E}}\left[\left(\frac{\sigma_{\mathrm{x}}+\sigma_{\mathrm{y}}}{2}\right)\left(\mathrm{r}+\frac{\mathrm{a}^{2}}{\mathrm{r}}\right)+\frac{\left(\sigma_{\mathrm{x}}+\sigma_{\mathrm{y}}\right)}{2}\left(\mathrm{r}-\frac{\mathrm{a}^{4}}{\mathrm{r}^{3}}+\frac{4 \mathrm{a}^{2}}{\mathrm{r}}\right) \cos 2 \theta\right] \\
-\frac{\mathrm{v}(1+\mathrm{v})}{\mathrm{E}}\left[\frac{\left(\sigma_{\mathrm{x}}+\sigma_{\mathrm{y}}\right)}{2}\left(\mathrm{r}-\frac{\mathrm{a}^{2}}{\mathrm{r}}\right)-\frac{\left(\sigma_{\mathrm{x}}+\sigma_{\mathrm{y}}\right)}{2}\left(\mathrm{r}-\frac{\mathrm{a}^{4}}{\mathrm{r}^{3}}\right) \cos 2 \theta\right]
\end{gathered}
$$

where:

$$
\begin{aligned}
& \sigma_{x} \sigma_{y}=\text { horizontal principal stresses in } x \text { and } z \text { direction }\left(\sigma_{x}=\sigma_{y}\right) . \\
& \theta \quad=\text { central angle with axis of the borehole. }
\end{aligned}
$$

When $r=a$, i.e. at the boundary of the borehole:

$$
\mathrm{u}=\frac{1-\mathrm{v}^{2}}{\mathrm{E}}\left[\mathrm{a}\left(\sigma_{\mathrm{x}}+\sigma_{\mathrm{y}}\right)+2 \mathrm{a}\left(\sigma_{\mathrm{x}}-\sigma_{\mathrm{y}}\right) \cos 2 \theta\right]
$$

Skotnicki and Raisbeck (1985) estimate the in situ horizontal stress relief on excavation of the western batters in Yallourn open cut coalmine to be $500 \mathrm{kPa}$. In such cases, as the mine face approaches the borehole and the horizontal stress progressively reduces and becomes zero ( $\sigma_{y} 100 \%$ to approaches $0 \%$ ), that is when only perpendicular stress (in $x$-direction) is acting on the borehole and a uniaxial loading condition develops, the horizontal displacement $\mathrm{u}$ at $r=a$ is:

$$
\mathrm{u}=\frac{\mathrm{a} \sigma_{\mathrm{y}}\left(1-\mathrm{v}^{2}\right)}{\mathrm{E}}(1-2 \cos 2 \theta)
$$

When this happens, according to Equation 3, as the horizontal stress in $x$-direction goes from $\sigma x$ to zero, the radial deformation goes from 5.34 to $2.67 \mathrm{~mm}$ in the $y$-direction $\left(\theta=90^{\circ}\right)$. This indicates the elongation of the borehole in the direction of the approaching mine batter ( $x$-direction), changing from circular to elliptical shape until critical pressure is reached and the borehole then collapses. As the borehole deforms over time due to time dependent mechanical creep under constant loading or due to an approaching mine face, the material around the borehole softens which means the elastic modulus decreases and the radial deformations increase (as indicated by Equations 3 and 4). 


\section{Table 1 Assumed mean values of key geotechnical parameters for modelling pore} pressure in a borehole in Victorian brown coal

\begin{tabular}{cc}
\hline Geotechnical parameter for Victorian brown coal & Mean value (assumed) \\
\hline C (cohesion) & $160 \mathrm{kPa}$ \\
$\phi$ (Angle of internal friction) & $35.5^{\circ}$ \\
Poisson's ratio & 0.39 \\
Specific gravity & 1.0 \\
Uniaxial compressive stress ( $\left.\mathrm{C}_{0}\right)$ & $0.62 \mathrm{MPa}$ \\
Ratio between horizontal and vertical stress ( $\left.\mathrm{K}_{0}\right)$ & 0.62 \\
$\mathrm{~m}_{\mathrm{i}}$ & 10 \\
GSI (considering the blocky and fair texture) & 45 \\
\hline
\end{tabular}

The values of key geotechnical parameters based on results presented in past literature describing the geomechanics of Victorian brown coal are listed in Table 1. The pore pressure dependent stresses and deformation in a brown coal borehole can be modelled using Kirsch equations (Equations 2 and 3) and Mohr-Colomb criteria under triaxial stress conditions.

To model the effect of an approaching mine face (from $y$-direction) on the underground stress field, the authors assume the horizontal stress in the direction of the approaching mine face to half (reduce in three steps). As the difference between the two principal horizontal stresses $\left(\sigma_{x}\right.$ and $\left.\sigma_{y}\right)$ increase from $\sigma_{y}=\sigma_{x}$, $\sigma_{y}=0.75 \sigma_{x}$ and $\sigma_{y}=0.5 \sigma_{x}$, the shape of failure zone around the borehole changes from circular to elliptical shape until critical pressure is reached. Figure 4 depicts the distortion of the borehole and the thickness of the failed zone outside the borehole wall, where it is observed that the inner walls deform and the borehole elongates in the direction of the approaching mine face ( $y$-direction).

Depth below surface $=300 \mathrm{~m}, \mathrm{~K}_{0}=0.65$, horizontal field stress Sigma $\mathrm{Hx}=1.9 \mathrm{MPa}$ Coal cohesion $=160 \mathrm{kPa}$, phi $=35.5^{\circ}$, density $=1.00$
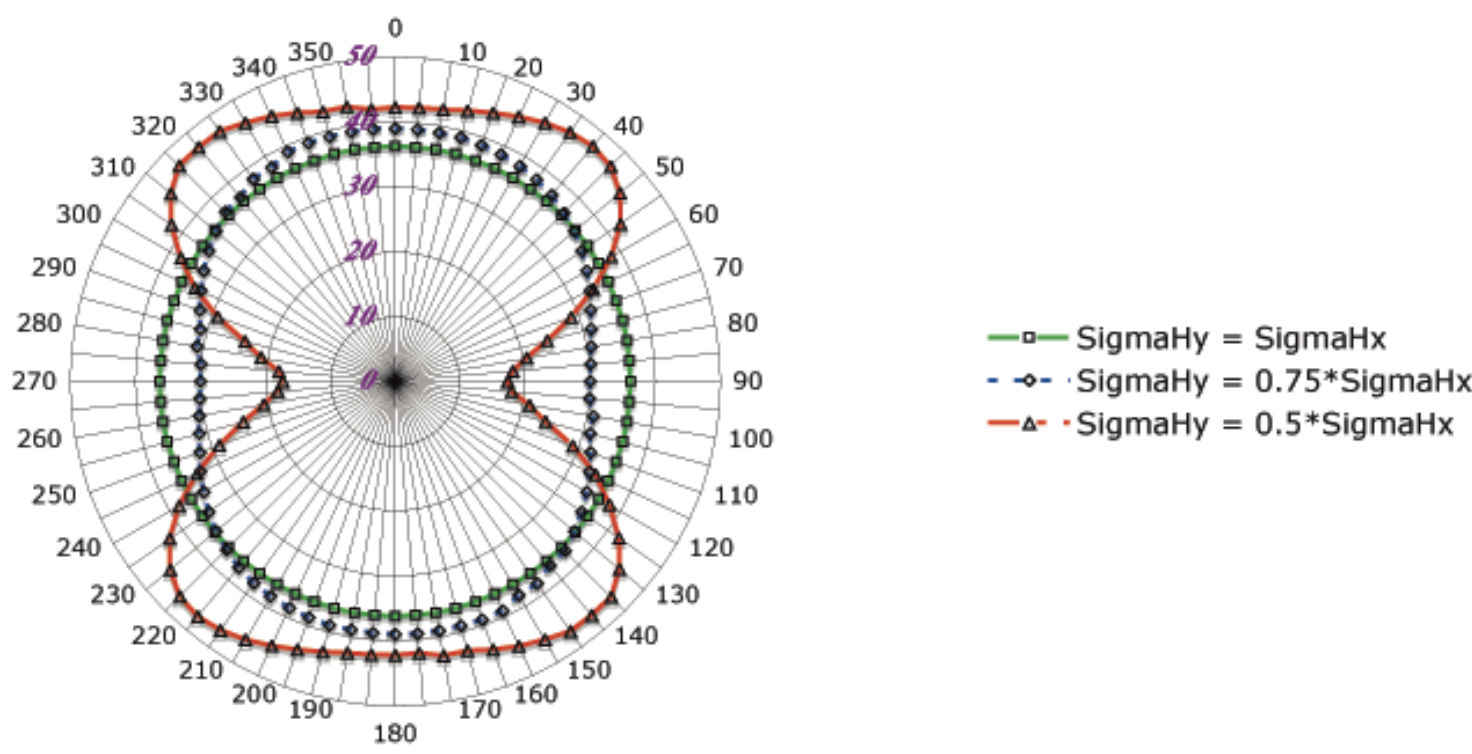

Figure 4 Thickness of the failed zone outside the borehole wall during a three-step reduction in horizontal stress 
The internal fluid pressure in the borehole walls drops steadily with time (or as the fluid is pumped out of the borehole after drilling operation) and the effect of this drop pressure causes dramatic deformation of the borehole and results in the enlargement of plastic zone around the borehole as shown in Figure 4 . The effects of the reduction on internal fluid pressure at the borehole wall on the thickness of the plastic zone around the borehole and the internal radial deformation calculated from Kirsch equations are also depicted in Figures $5(\mathrm{a})$ and (b).

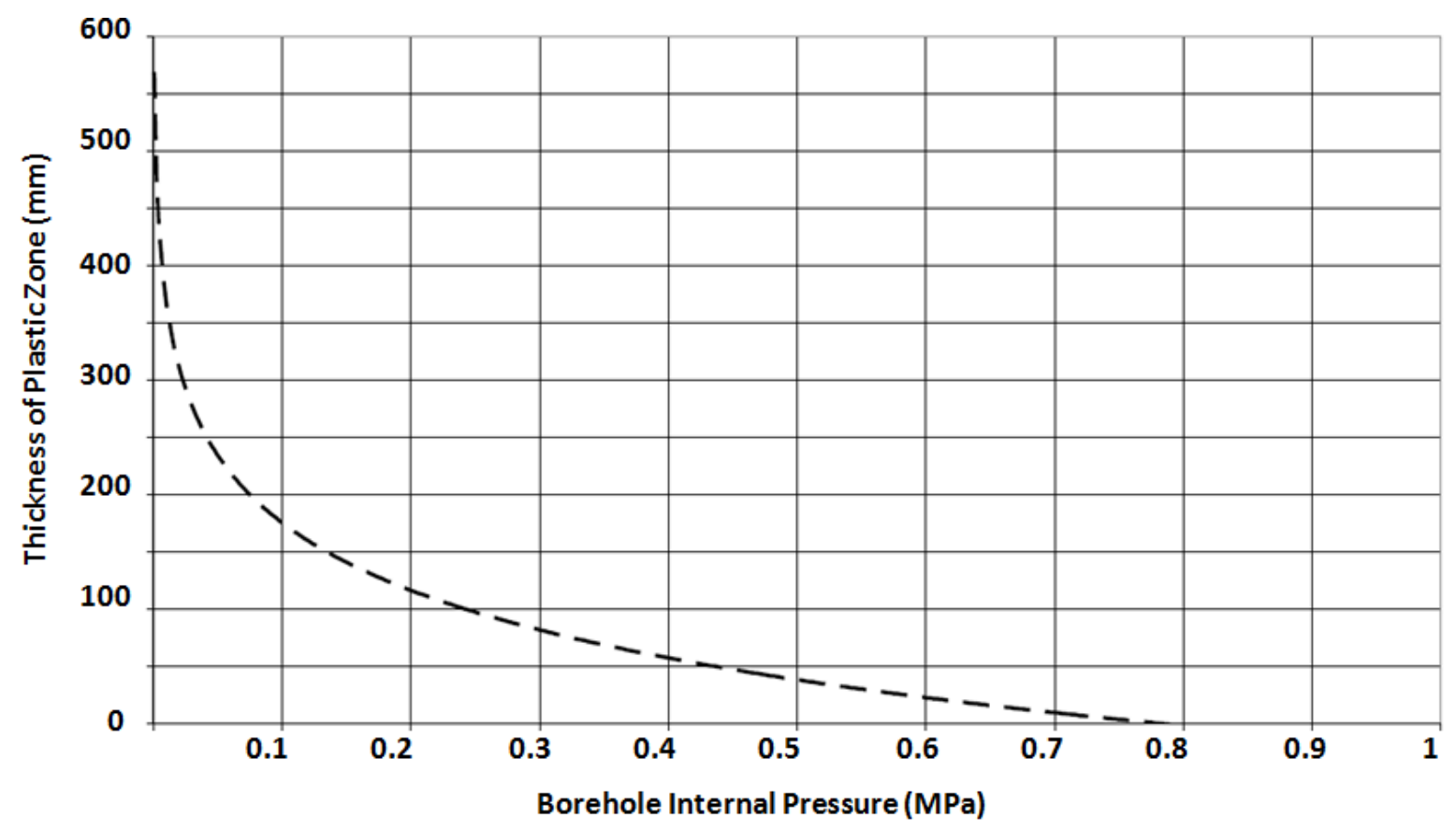

(a)

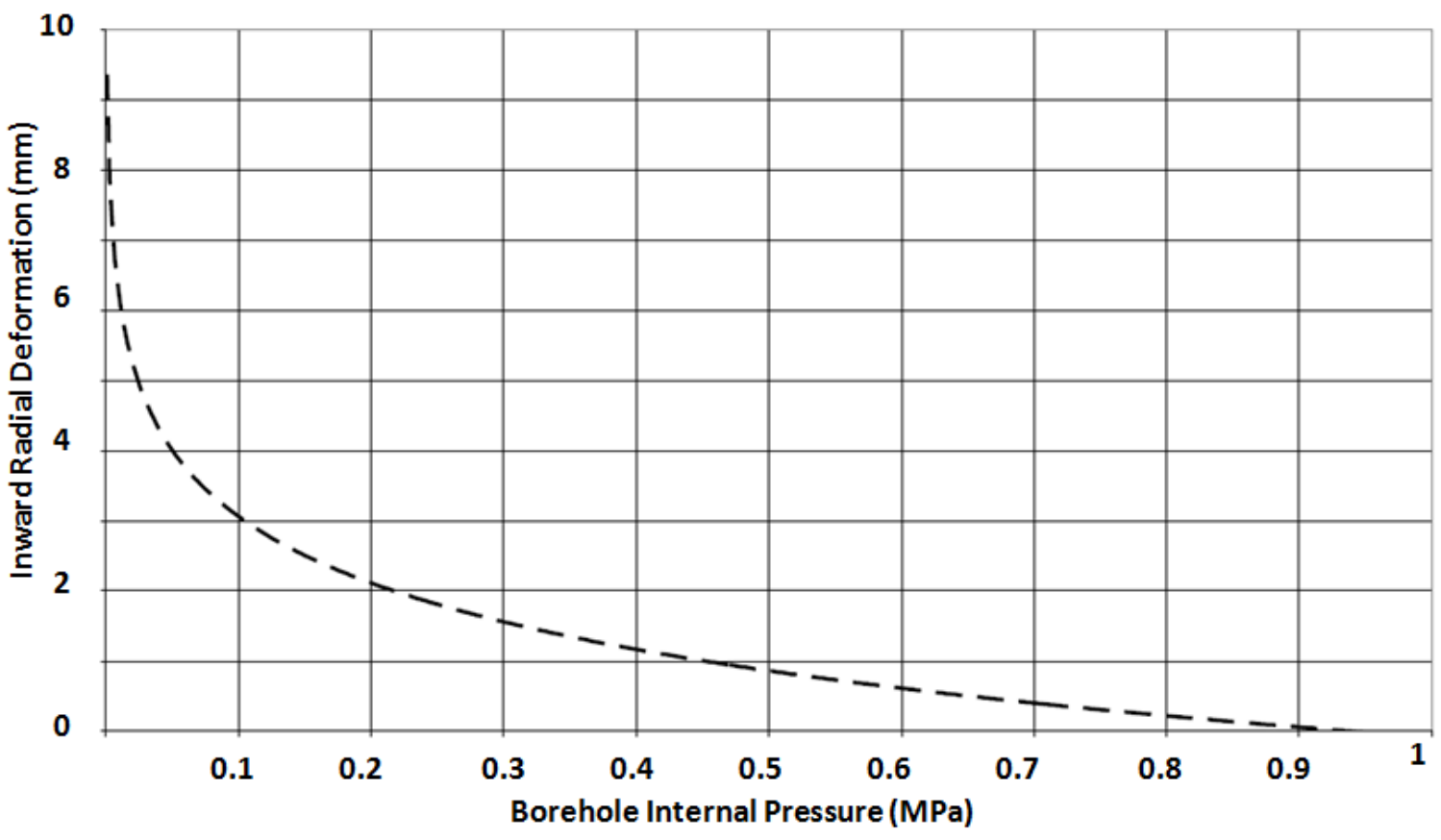

(b)

Figure 5 (a) effect of reducing borehole internal pressure on thickness of the plastic zone around the borehole walls; (b) inward radial deformation of the borehole due to change in borehole internal pressure 
Figure 6 shows the change in relationship between the radius of the borehole to the radius of the plastic zone resulting from the reduction of borehole internal pressure. As the internal pressure drops from $3 \mathrm{MPa}$ to $0 \mathrm{MPa}$ and the borehole becomes increasingly unstable, the model predicts the overall safety factor (calculated from Mohr-Coulomb criteria for triaxial stress conditions) of the borehole reducing from 4.5 to 0.2 , as shown in Figure 7.

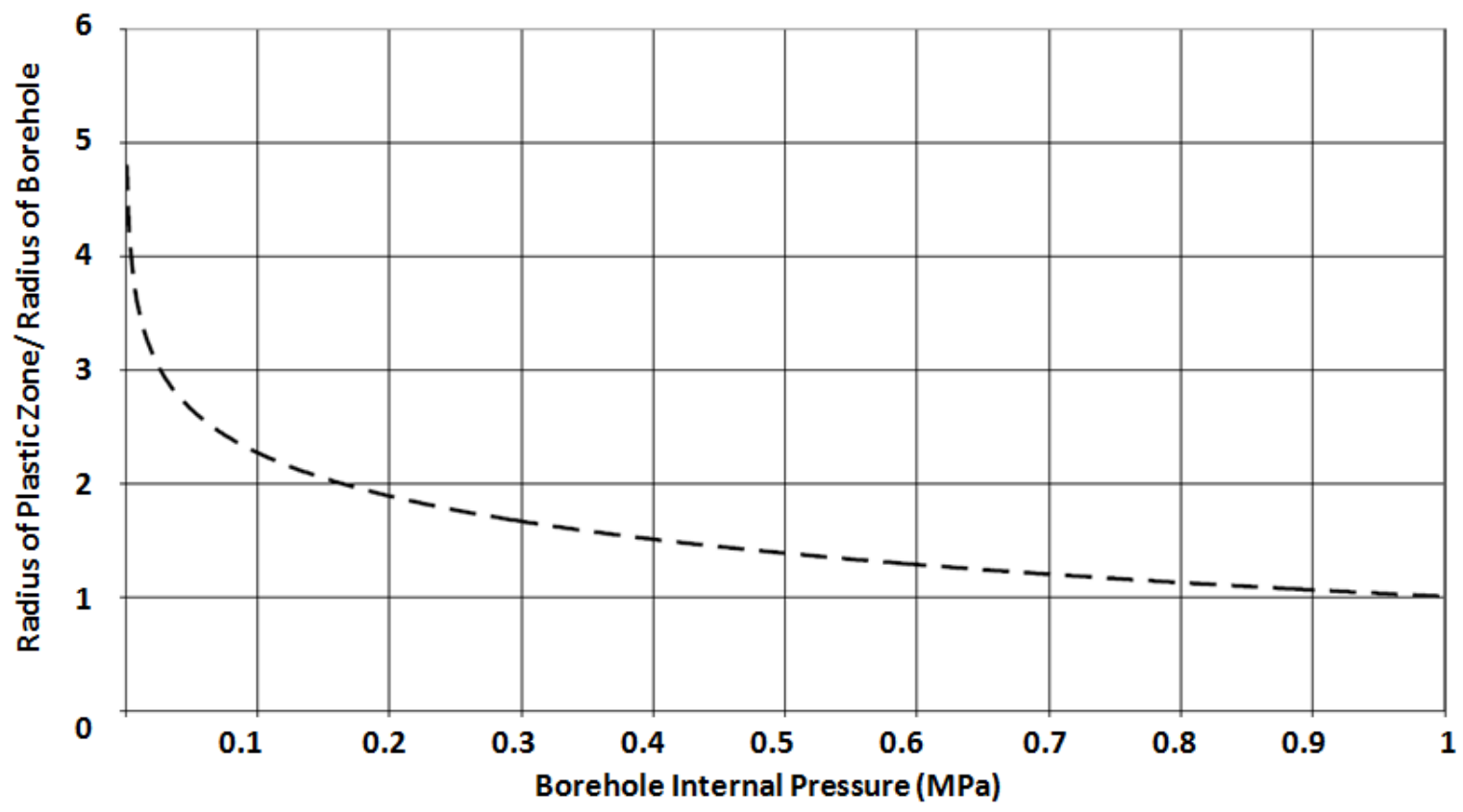

Figure 6 Change in relationship between radius of plastic zone and radius of the borehole due to decreasing internal pressure

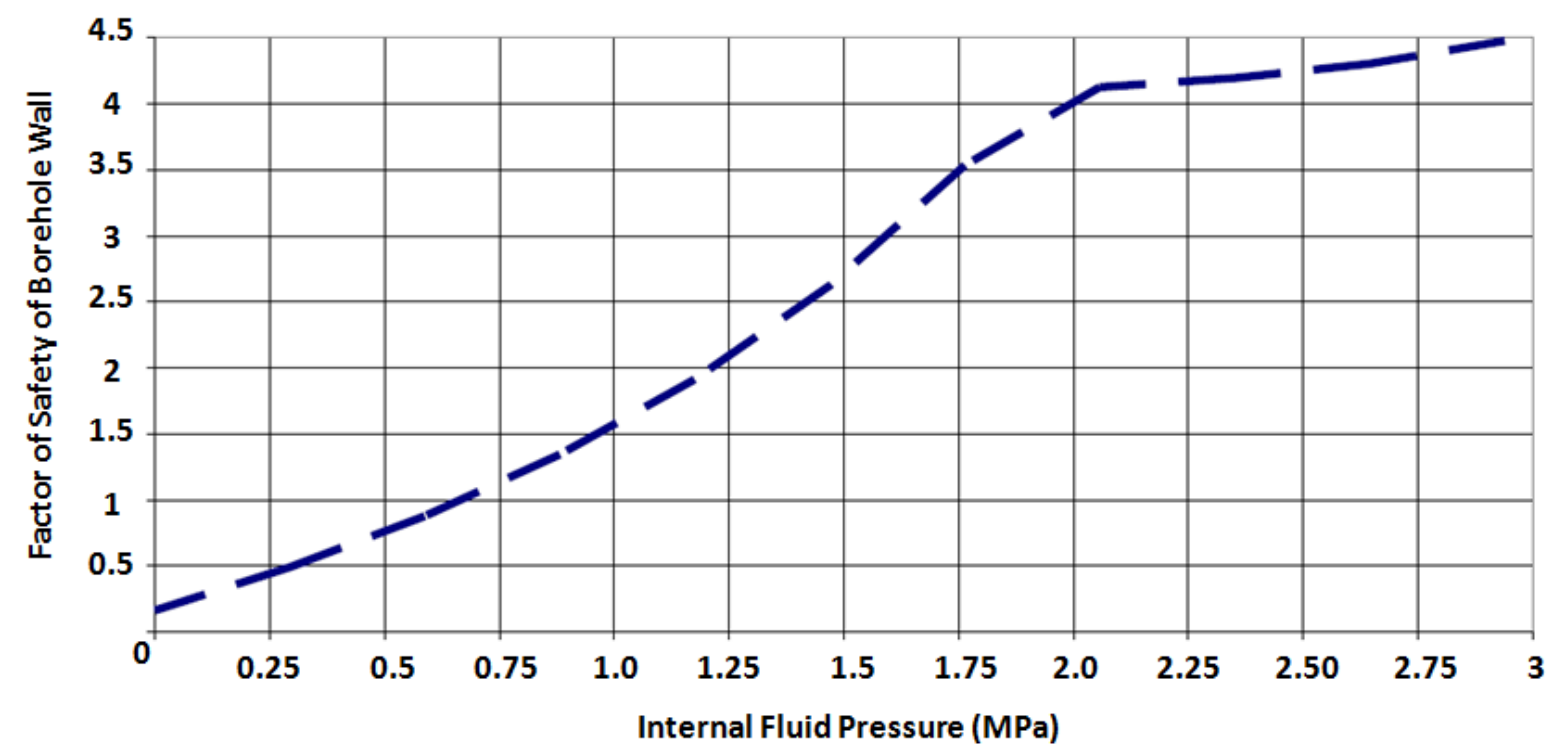

Figure 7 Safety factor reduction due to internal fluid pressure reduction

\section{$5 \quad$ Time dependent creep in brown coal}

Rocks under constant loading slowly creep and deform under the stress. The three stages of mechanical creep consist of a primary state when the strain rate decreases and plateaus until it increases again in the secondary stage and then moves into the tertiary stage which ultimately leads to rock failure. The time dependent creep in many rocks like granite (Lockner 1993), limestones (Brantut et al. 2013), and sandstones (Heap et al. 2009) has been thoroughly investigated and established in the past, but in the case 
of more heterogeneous rocks like brown coal, the relationship between the creep rate and other experimental parameters is hard to determine and hence would require special experimental programs to ensure higher repeatability of results.

Pomeroy (1956) conducted creep measurement on some coals and reported the absence of creep in anthracites, which resulted in explosive failure of the anthracite specimens as the breaking strength, is readily exceeded upon loading. Amitrano and Helmstetter (2006) developed finite element models of creeping process in brown coal and reported a power law distribution of damage event sizes until microscopic damage. They also point to the emergence of damage localisation resulting in highly damaged bands towards the final stage of simulation. Their numerical model suggests that complex macroscopic behaviour develops in the brown coal substructure due to elastic interactions between elements and heterogeneity of the mechanical properties of brown coal. The effect of these mechanisms related to mechanical creep on boreholes in brown coal is yet to be studied in detail.

\section{Other time dependent characteristics of brown coal}

Other properties of brown coal such as carbon fibre content, decompositional stage of the coal, and variables like natural moisture content, temperature and chemical changes in the coal that may occur in the time between borehole drilling and laboratory experiments also need to be incorporated. Couling et al. (2014), report that brown coal is likely to contain a gas other than air trapped in its micropores, which suggests that using a more soil-mechanics inspired approach would be more suitable in dealing with Victorian brown coal. Concepts relating to multiphase fluid mechanics and hydrodynamics would be a suitable method for analysing the compressibility and mechanical behaviour of brown coal hence the rock mechanical methodologies, which are commonly applied to borehole analysis, may not be the best way to go. The quasi-saturated state of Victorian brown coal at shallow depths means that there is a high probability of existence of compressible gas bubbles in the pores. Internal micro-cracking may be promoted by the high pressure of entrapped gas present in the micro pores in brown coal matrix at different stages of loading and unloading. Such additional creeping in conjunction with the mechanical creep, leads to unusually high and unpredictable time dependent deformation patterns in the coal mass.

The prolonged exposure to oxygen causing spontaneous oxidation of brown coal (Tessler \& Jehlicka 1989) and slow release of internal gas (Freudenstein et al. 2000) from the exposed coal surfaces (for example in the inner walls of a borehole) also alters the chemical as well as engineering properties of coal, causing further problems in predicting its geotechnical behaviour. The shrinkage of coal is also a factor that must have a prominent effect on borehole deformation as brown coal tends to shrink by $20-60 \%$ as it goes from a moist state to air dried state (George 1982).

\section{Conclusion}

The model presented in this paper suggests that deformation of the borehole walls resulting from change in underground stress conditions, such as from an approaching mine face, can severely hamper the stability of the borehole. This possible distortion of the borehole and plastic failure of the surrounding brown coal, may alter the data obtained from any ground monitoring systems installed in the borehole with potential for partial or complete loss of the equipment. Hence, extreme caution and detailed analysis of the site must be undertaken before planning the location of a borehole or planning of a mining operation in vicinity of an existing borehole.

The presence of time-dependent inelastic creep, swelling and shrinkage of brown coal have substantial roles to play in the time dependent failure of boreholes and hence must be studied in detail particularly keeping the volatility of brown coal as a geomaterial in mind. Time dependent failure of brown coal boreholes deserves attention and further research on the effects of different environmental, chemical as well as mechanical factors that affect the behaviour of brown coal is essential to completely understand the behaviour of boreholes in brown coal. The contribution of slow pore gas release on the mechanical 
characteristics of the borehole walls should also be investigated further to complement the development of a comprehensive model of time dependent behaviour of boreholes in brown coal.

\section{References}

Amitrano, D \& Helmstetter, A 2006, 'Brittle creep, damage, and time to failure in rocks', Journal of Geophysical Research: Solid Earth, vol. 111, no. B11, p. 111.

Backers, T 2013, 'Borehole geomechanics and well design', in IGA Service GmbH (comp.), IGA Academy Report, vol. 1, IGA Service GmbH, Bochum, viewed 3 March 2015, http://www.geothermal-energy.org/iga_academy/ifc_workshop_izmir.html?no_ cache $=1 \&$ cid $=867 \&$ did $=324 \&$ sechash $=250 \mathrm{e} 741 \mathrm{~b}$

Brantut, N, Heap, MP, Meredith, P \& Baud, P 2013, 'Time-dependent cracking and brittle creep in crustal rocks: a review', Journal of Structural Geology, vol. 52, pp. 17-43.

Couling, C, Tolooiyan, A, Mackay, R \& Xue, J 2014, 'Measurement of pore water pressure properties of unsaturated brown coal using triaxial test', in N Khalili, AR Russell \& A Khoshghalb (eds), Unsaturated Soils: Research and Applications, Proceedings of the 6th International Conference on Unsaturated Soils, CRC Press/Balkema, Netherlands, vol. 2, pp. 1531-1535.

Freudenstein, U, Crowley, D \& Welch, F 2000, 'Chemical incident management: gaseous emissions from a stockpile of coal', Public Health, vol. 114, no. 1, pp. 41-44.

George, AM 1982, 'Latrobe Valley brown coal - lithotypes: macerals: coal properties', in CW Mallett (ed.), Proceedings of the Symposium on Coal Resources: Origin, Exploration and Utilisation in Australia, Geological Society of Australia, Melbourne, pp. 111-130.

Guenot, A 1989, 'Borehole breakouts and stress fields', International Journal of Rock Mechanics and Mining Sciences \& Geomechanics Abstracts, vol. 26, no. 3, pp. 185-195.

Haimson, B 2007, 'Micromechanisms of borehole instability leading to breakouts in rocks', International Journal of Rock Mechanics and Mining Sciences, vol. 44, no. 2, pp. 157-173.

Heap, MJ, Baud, P, Meredith, PG, Bell, AF \& Main, IG 2009, 'Time-dependent brittle creep in Darley Dale sandstone', Journal of Geophysical Research, vol. 114, no. B7, p. 203.

Heap, MJ, Faulkner, DR, Meredith, PG \& Vinciguerra, S 2010, 'Elastic moduli evolution and accompanying stress changes with increasing crack damage: implications for stress changes around fault zones and volcanoes during deformation', Geophysical Journal International, vol. 183, no. 1, pp. 225-236.

Hsieh, A, Dyskin, AV \& Dight, P 2014, 'The increase in Young's modulus of rocks under uniaxial compression', International Journal of Rock Mechanics \& Mining Sciences, vol. 70, pp. 425-434.

Hutton, AC 2009, 'Geological setting of Australasian coal deposits', in R Kininmonth \& E Baafi (eds), Australasian coal mining practice, The Australasian Institute of Mining and Metallurgy, Victoria, pp. 40-84.

Lockner, DA 1993, 'Room temperature creep in saturated granite', Journal of Geophysical Research, vol. 98, no. B1, pp. $475-487$.

Pomeroy, CD 1956, 'Creep in coal at room temperature', Nature, vol. 178, pp. 279-280.

Ramamurthy, T (ed.) 2014, Engineering in Rocks for Slopes, Foundations and Tunnels, PHI Learning Private Ltd, Delhi.

Schoenball, M, Sahara, DP \& Kohl, T 2014, 'Time-dependent brittle creep as a mechanism for time-delayed wellbore failure', International Journal of Rock Mechanics and Mining Sciences, vol. 70, pp. 400-406.

Skotnicki, AL \& Raisbeck, D (1985), 'Report on Yallourn Open Cut, earthmovement analyses for the western and northern batters. SECV Design Engineering and Environment Department, Report No. GD32.

Tessler, J \& Jehlicka, O 1989, Deterioration of brown coal during open-air storage', Bulk Solids Handling, vol. 9, no. 4, pp. 427-428.

Trollope, DH, Rosengren, KJ \& Brown, ET 1965, 'The mechanics of brown coal', Geotechnique, vol. 15, no. 4, pp. 363-386.

Zoback, MD, Moos, D, Mastin, L \& Anderson, RN 1985, 'Well bore breakouts and in situ stress', Journal of Geophysical Research, vol. 90, no. B7, pp. 5523-5530. 